\title{
HÍBRIDOS INORGÂNICO-ORGÂNICOS DERIVADOS DA REAÇÃO DE FILOSSICATOS COM ORGANOSSILANOS
}

Maria Gardênnia da Fonseca

Departamento de Química, Universidade Federal da Paraíba, Cidade Universitária, 58050-970 João Pessoa - PB

Claudio Airoldi*

Instituto de Química, Universidade Estadual de Campinas, CP 6154, 13084-971 Campinas - SP

Recebido em 24/6/02; aceito em 24/2/03

INORGANIC-ORGANIC HYBRIDS DERIVED FROM THE REACTION OF PHYLLOSILICATES WITH ORGANOSILANES. Silylation reactions involving hydroxylated surfaces are an important route for synthesis of new materials that could present selected properties, for application in different areas such as catalysis, chromatography, adsorption and electrochemistry. An overview of many synthetic routes, comprising organosilanes to yield phyllosilicates is now presented.

Keywords: inorganic-organic hybrids; phylosilicates; silytation.

\section{INTRODUÇÃO}

Nestas últimas décadas, uma variedade de superfícies passou a despertar enorme interesse em aplicações, desde que se iniciou o processo de imobilização nesses suportes, graças ao uso de agentes sililantes. Esses agentes possibilitam a fixação de moléculas covalentemente em superfícies, sendo que diferentes grupos funcionais podem fazer parte das estruturas moleculares ancoradas ${ }^{1}$.

Dentre essas superfícies inorgânicas sobressai à sílica gel, que continua sendo muito procurada para efetivação dos vários processos envolvidos na modificação química, com o intuito de se vislumbrar aplicações tanto do ponto de vista acadêmico como tecnológico ${ }^{1,2}$. De maneira idêntica à sílica, inúmeros materiais naturais ou sintéticos, como exemplo os minerais, também dispõem de grupos hidroxilados sobre a superfície, os quais desempenham papel fundamental na habilidade em reagir. No caso particular dos minerais argilosos, as suas propriedades lamelares permitem modificações químicas, que ocorrem por reações de intercalação de moléculas orgânicas ou troca dos cátions originalmente presentes nas lacunas interlamelares. Essa rota é eficaz para que se processe a imobilização de catalisadores complexos na estrutura de minerais, tornando possível a efetivação de reações no estado sólido, com grande semelhança àquelas que ocorrem em solução ${ }^{3}$. Este fato minimiza muitas barreiras técnicas e tecnológicas associadas ao uso desses complexos como catalisadores homogêneos.

Apesar da facilidade experimental de algumas dessas reações, o interesse por compostos sintéticos aumentou desde que se puderam obter materiais com composição química definida e sem a presença de impurezas. Aspectos estruturais também podem ser controlados, de forma que, tanto estruturas cristalinas como defeituosas, podem ser sintetizadas, direcionando-as para aplicações mais específicas como, por exemplo, a catálise. Neste particular, destacam-se mais recentemente os filossilicatos modificados organicamente, os quais tiveram um grande impulso preparativo com o domínio do processo sol-gel ${ }^{4-12}$. Desse modo, a obtenção de novas estruturas, bem como o estudo mais detalhado das condições experimentais, aplicação desses novos compostos e até modelagem de sistemas, são importantes na tentativa de descoberta de novos materiais.

*e-mail: airoldi@iqm.unicamp.br
No âmbito dessa abordagem uma revisão será apresentada, envolvendo algumas considerações sobre os métodos de modificação química de superfícies hidroxiladas com grupos orgânicos derivados dos agentes sililantes, destacando-se principalmente a aplicação dos compostos com arranjo cristalino denominados filossilicatos.

\section{UMA BREVE ABORDAGEM SOBRE SILICATOS}

A classe mineral dos silicatos é de maior importância, superando qualquer outra, pois cerca de $25 \%$ dos minerais conhecidos e quase $40 \%$ dos minerais comuns são silicatos. Sabe-se que os minerais dominantes da crosta terrestre são os silicatos e óxidos, cujas propriedades dependem das condições físicas e químicas de sua formação ${ }^{13}$. Os silicatos são compostos formados por unidades estruturais extremamente estáveis contendo tetraedros, representados por $\mathrm{SiO}_{4}$ que, dependendo do tipo de polimerização envolvido, pode formar diferentes grupos de compostos. Constata-se que há relação entre as condições de origem dos silicatos e o grau de polimerização ${ }^{13}$. Dependendo desta propriedade de polimerização e da amplitude da participação de oxigênio entre os tetraedros, a estrutura dos silicatos pode consistir em tetraedros independentes, como arranjos de grupos tetraédricos múltiplos, independentes, cadeias simples, cadeias duplas ou faixas, folhas ou armações tridimensionais ${ }^{13}$. Assim, conforme o arranjo, os silicatos podem ser agrupados em classes, como mostra a Tabela 1 .

Tabela 1. Classificação dos silicatos de acordo com o arranjo dos grupos tetraédricos $\mathrm{SiO}_{4}$

\begin{tabular}{ll}
\hline Classe & Arranjos dos tetraedros $\mathrm{SiO}_{4}$ \\
\hline Nesossilicatos & Isolados \\
Sorossilicatos & Duplos \\
Ciclossilicatos & Anéis \\
Inossilicatos & Cadeias simples ou duplas \\
Filossilicatos & Folhas \\
Tectossilicatos & Estruturas tridimensionais \\
\hline
\end{tabular}

Dentre as várias classes, a dos filossilicatos é a que possui maior participação dentro da química de materiais. Porém, inseridos nesta 
classe encontram-se os minerais argilosos, que são mais extensamente investigados. Do ponto de vista químico, esses minerais são silicatos que contêm basicamente alumínio e magnésio (podendo conter outros elementos, como $\mathrm{Fe}, \mathrm{Ca}, \mathrm{Na}, \mathrm{K}$ e outros), sendo que na composição geral, invariavelmente acompanham moléculas de água e se apresentam em uma estrutura lamelar ou fibrosa ${ }^{14}$.

Compõe essa estrutura grupos de composição $\mathrm{TO}_{4}$, sendo que $\mathrm{T}$ representa um cátion em coordenação tetraédrica normalmente $\mathrm{Si}^{4+}$, $\mathrm{Al}^{3+}$ ou $\mathrm{Fe}^{3+}$, que estão unidos entre si formando uma camada tetraédrica. A camada tetraédrica está constituída por hexágonos formados de 6 tetraedros unidos entre si, contendo em seus vértices oxigênios com valências livres, apontando no mesmo sentido, conforme mostra a Figura 1.
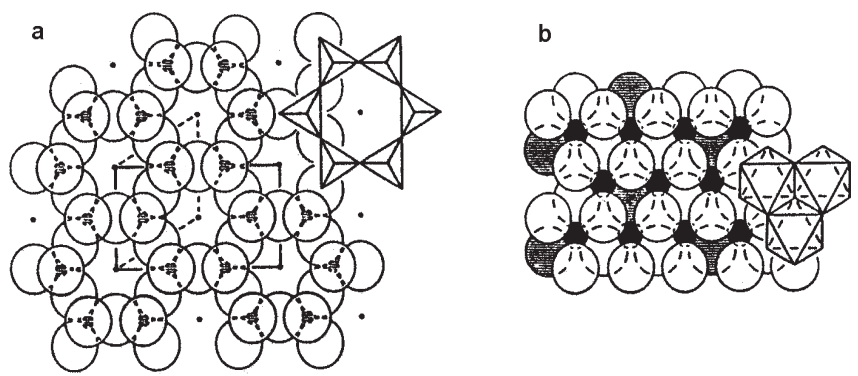

Figura 1. Constituintes dos filossilicatos: a) visão planar de uma camada tetraédrica hexagonal ideal e b) camada octaédrica com grupos hidroxila no interior

Cada uma dessas camadas poderá unir-se a outra, como por exemplo, unidades octaédricas de hidróxidos metálicos que tenham valências livres apontando em sentido oposto, em relação à camada tetraédrica, formando uma estrutura do tipo 1:1. Um outro arranjo poderá ser obtido pela união de duas camadas tetraédricas em sanduíche com uma octaédrica originando as estruturas denominadas 2:1. Uma ilustração desses arranjos pode ser visualizado na Figura 2. a

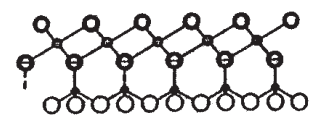

Lamela 1:1

- Cátion Tetraédrico

- Cátion Octaédrico b

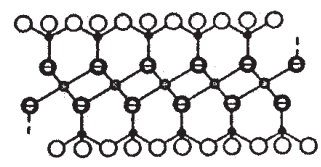

Lamela 2:1

O Oxigênio

• Oxigênio $+\mathrm{OH}$ (em projeção)

- Grupo $\mathrm{OH}$
Figura 2. Representação dos arranjos de filossilicatos do tipo a) 1:1 e b) 2:1

Conforme se observa na Figura 2, o plano comum de junção entre as camadas tetraédricas e octaédricas consiste de oxigênios axiais e grupos $\mathrm{OH}$ não compartilhados. Porém, em algumas espécies o íon fluoreto pode substituir o grupo $\mathrm{OH}$. Nos filossilicatos, a maior parte possui hidroxilas e as peculiaridades estruturais associadas com esse íon são de enorme importância para a determinação de suas propriedades. Os cátions octaédricos mais comumente encontrados nestes tipos de compostos são $\mathrm{Mg}^{2+}, \mathrm{Al}^{3+}, \mathrm{Fe}^{2+}$ e $\mathrm{Fe}^{3+}$, mas outros cátions como $\mathrm{Li}, \mathrm{Ti}, \mathrm{V}, \mathrm{Cr}, \mathrm{Mn}, \mathrm{Co}, \mathrm{Ni}, \mathrm{Cu}$ e $\mathrm{Zn}$ também podem ocorrer em algumas espécies ${ }^{15-18}$.

As camadas crescem nas direções a e b e estão empilhadas ao longo do eixo c. Esse empilhamento poderá ser organizado ou não, neste último caso tem-se a formação das estruturas denominadas turbostráticas conforme ilustra a Figura 3. (a)

(b)
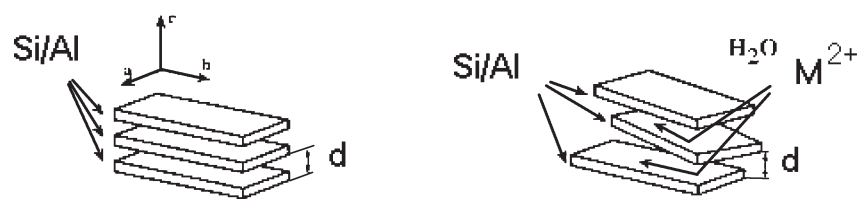

Figura 3. Empilhamento de folhas ao longo do eixo $c$ a) ordenado e b) desordenado (estruturas turbostráticas)

A ocorrência de substituições isomórficas de íons de carga distinta na rede faz com que as camadas 1:1 e 2:1 não estejam eletricamente neutras. Assim, o excesso de carga é neutralizado por vários tipos de espécies interlamelares como cátions individuais, cátions hidratados e grupos de hidróxidos ${ }^{15}$. Quando as lamelas são eletricamente neutras, a região interlamelar se encontra vazia e as lamelas adjacentes são mantidas através de interações fracas, do tipo van der Waals.

A menor unidade estrutural contém três octaedros. Se todos os três estão ocupados com o cátion octaedricamente coordenado em seu centro, a camada é classificada como trioctaédrica. Se apenas dois dos octaedros estão ocupados e o terceiro está vago, a camada é classificada como dioctaédrica ${ }^{16}$.

Os filossilicatos estão, portanto, classificados convenientemente com base no tipo de lamela 1:1 ou 2:1, carga da lamela e tipo de espécie interlamelar, em oito grupos. Esses grupos são ainda subdivididos de acordo com o tipo de camada octaédrica (di ou tri), composição química, geometria da superposição das camadas individuais e região interlamelar ${ }^{15}$, conforme mostra a Tabela 2.

Um aspecto importante em cada uma das espécies de filossilicatos é a ligação química prevalecente nas lacunas intercalares, dentre elas estão: interação do tipo O-O no talco; interação OH-O (ligação de hidrogênio) na caulinita, antigorita e clorita; interação $\mathrm{H}_{2} \mathrm{O}-\mathrm{O}$ na haloisita; interação cátion trocável- $\mathrm{H}_{2} \mathrm{O}-\mathrm{O}$ nas esmectitas e vermiculitas; interação cátion interlamelar $\mathrm{K}^{+}$ou $\mathrm{Na}^{+}-\mathrm{O}$ nas ilitas ${ }^{18}$.

As modificações químicas desses materiais possibilitam, no geral, o desenvolvimento de reações que ocorrem somente na superfície, como na lacuna interlamelar, dependendo do tipo de filossilicato. Para lamela não expansível, apesar dessa classificação, a obtenção de derivados de intercalação já foi realizada com sucesso, como para a caulinita, cuja primeira reação de intercalação foi feita na década de setenta com sais de potássio, rubídio, césio e amônio derivados de ácidos carboxílicos ${ }^{18}$. Posteriormente, as intercalações de compostos orgânicos tais como uréia, formamida, metilformamida, dimetilformamida, dimetilsulfóxido e hidrato de hidrazina também foram conseguidas ${ }^{19-25}$. No Brasil, um excelente trabalho foi descrito, recentemente, envolvendo a intercalação e esfoliação nesse filossilicato com uréia ${ }^{26}$.

Por outro lado, para os filossilicatos expansíveis como as esmectitas, várias reações no espaço interlamelar envolvendo processos de troca iônica e intercalação de moléculas neutras, complexos metálicos, polímeros ou organocátions têm sido reportadas. Desse modo, uma grande diversidade de reações e, portanto, novos materiais podem ser explorados. Devido à complexidade do assunto, além da grande extensão do tema, o enfoque aqui será limitado às reações que visam os compostos derivados orgânicos de filossilicatos naturais e sintéticos, através do uso de agentes sililantes ou silanos.

\section{OBTENÇÃO DE FILOSSILICATOS ORGANICAMENTE MODIFICADOS}

A síntese de materiais híbridos pode ser feita por vários métodos 
Tabela 2 - Classificação dos filossilicatos relacionados aos minerais argilosos, considerando o tipo de lamela (Tipo), grupo (Grupo) com carga da fórmula (x), subgrupo (Subg) e exemplo das espécies (Esp)

\begin{tabular}{llll}
\hline Tipo & Grupo & Subg & Esp \\
\hline $1: 1$ & Serpentina-caulin & Serpentina & Crisotila, antigorita \\
& $\mathrm{x} \sim 0$ & Caulin & Caulinita, nacrita \\
$2: 1$ & Talco-pirofilita & Talco & Talco, willemseita \\
& $\mathrm{x} \sim 0$ & Pirofilita & Pirofilita \\
& Esmectita & Saponita & Saponita, hectorita \\
& $\mathrm{x} \sim 0,2-0,6$ & Montmorrilonita & Montmorrilonita, beidelita \\
& Vermiculita & Trioctaédrica & Vermiculita trioctaédrica \\
& $\mathrm{x} \sim 0,2-0,6$ & Dioctaédrica & Vermiculita dioctaédrica \\
& Mica & Trioctaédrica & Biotita, lepidolita \\
& $\mathrm{x} \sim 1$ & Dioctaédrica & Muscovita, paragonita \\
& Mica & Trioctaédrica & Clintonita \\
& $\mathrm{x} \sim 2$ & Dioctaédrica & Margarita \\
& Clorita & Trioctaédrica & Chamosita \\
& $\mathrm{x} \sim$ variável & Dioctaédrica & Donbassita \\
& & Di,trioctaédrica & Sudoita \\
& Sepiolita-paligorskita & Sepiolita & Sepiolita \\
& $\mathrm{x} \sim$ variável & Paligorskita & Paligorskita \\
\hline
\end{tabular}

como i) adsorção de espécies orgânicas nos poros de um suporte, ii) construção de moléculas orgânicas em várias etapas dentro dos poros de um suporte, iii) imobilização do grupo com a funcionalidade desejada no suporte pela formação de ligação covalente e iv) síntese direta formando um produto final ${ }^{27}$.

Dentre os métodos mais utilizados para os silicatos estão a síntese de silicatos híbridos inorgânico-orgânicos por reações que partem de uma matriz precursora, na qual um agente orgânico modificador é incorporado à superfície do material e/ou no espaço interlamelar, ou ainda, através do método sol-gel, no qual a fase inorgânica, quando formada, passa a incorporar simultaneamente um grupo orgânico em sua estrutura.

A escolha do método de obtenção dependerá da natureza do material e da aplicação a que este se destina. Geralmente, o propósito dessas reações é a obtenção de novos materiais com propriedades superiores à matriz inorgânica precursora. Dessa forma, é possível a combinação das vantagens da fase inorgânica, como altas estabilidades térmica e mecânica, resistência a solventes e ácidos, com aquelas do grupo orgânico. $\mathrm{O}$ material assim sintetizado reflete na sua capacidade de interagir com diversas espécies como íons, complexos metálicos, enzimas, proteínas, metaloporfirinas ou ftalocianinas. Um exemplo clássico poderia ser a utilização dessas matrizes em adsorção bioseletiva ${ }^{1}$. A idéia é a utilização de um suporte compatível com água, sendo inerte e mecanicamente durável. Desse modo, os primeiros materiais utilizados foram celulose e agarose por serem compatíveis com biomoléculas, enquanto que outros materiais como os plásticos foram descartados por serem hidrofóbicos e desnaturarem a proteína. Entretanto, a celulose por ser muito heterogênea e a agarose por ser compressível sobre altas pressões ou em colunas largas foram também descartadas para esse fim. Assim, a proposta mais viável foi o emprego de matrizes inorgânicas modificadas com grupos de funcionalidades específicas, por se mostrarem com bom desempenho para cromatografia líquida de alta eficiência, operando tanto em alta como em baixas pressões.

Desse modo, conforme a funcionalidade do grupo ancorado, pode-se alterar uma superfície hidrofílica em hidrofóbica ou lipofílica, direcionando a utilização dessas fases para fins cromatográficos específicos ${ }^{1}$.

\section{DERIVADOS ORGÂNICOS ENVOLVENDO REAÇÕES APENAS NA SUPERFÍCIE}

O processo de organofuncionalização de uma superfície consiste no uso de um modificador que contém um determinado grupo orgânico, neste caso um alquilalcoxissilano, que é ligado à superfície do suporte, geralmente por interação entre o radical alcoxi e as hidroxilas superficiais ${ }^{2}$. O grupo orgânico contido na extremidade da cadeia poderá sofrer novas reações, aumentando o número de espécies imobilizadas ${ }^{28}$, conforme a Figura 4.

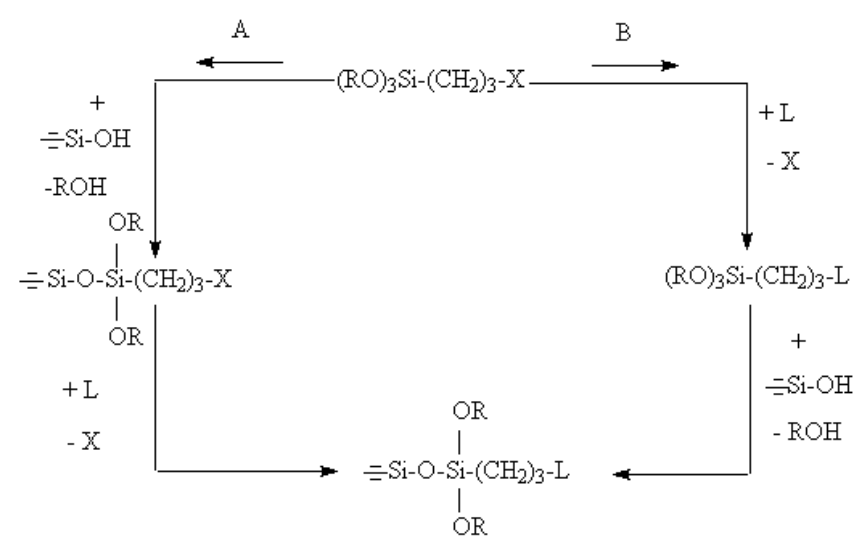

Figura 4. Rotas utilizadas para a imobilização de um grupo organofuncional sobre uma superficie hidroxilada A) heterogênea e B) homogênea

Esse procedimento experimental é bastante similar ao utilizado na obtenção de sílica gel modificada, como também de outros óxidos inorgânicos como $\mathrm{MoO}_{2}, \mathrm{SnO}_{2}$ e $\mathrm{Al}_{2} \mathrm{O}_{3}$. No processo de silanização de superfícies, dois métodos podem ser destacados²:

(a) Funcionalização por hidrólise de silanos em presença de água proveniente do substrato mineral, atmosfera ou gerada in situ. Nos métodos tradicionais, são utilizados os sistemas com solventes aquosos. No caso de um silano $\mathrm{R}_{\mathrm{n}} \mathrm{SiR}_{(\mathrm{n}-4)}$ em que R' é 
um grupo hidrolisável, os grupos silanóis resultantes da hidrólise de R' são usualmente lábeis e condensam formando ligações siloxanos com outros grupos silanóis, tanto na superfície do mineral como na solução. Tipicamente, os silanos hidrolisáveis condensam em solução aquosa, formando oligômeros siloxanos, os quais interagem com o substrato por ligação de hidrogênio. Uma representação da silanização em meio aquoso de um substrato por um organossilano contendo três grupos hidrolisáveis é mostrada na Figura 5.

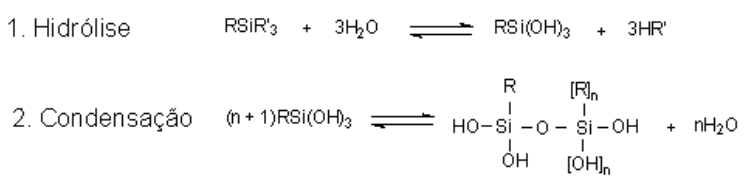

3. Ligação de hidrogênio 4. Formação da ligaçẫo
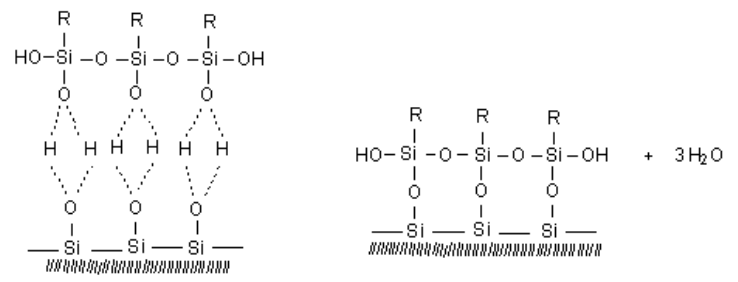

Figura 5. Representação de um dos mecanismos possíveis da interação de um agente sililante com superfícies inorgânicas em meio aquoso

Neste caso, freqüentemente ocorre um extensivo grau de ligações cruzadas, produzindo uma multicamada de silano tridimensional na superfície, ao invés de uma cobertura de monocamada bidimensional. Estes estudos constatam que a silanização em múltiplas camadas resulta em produtos instáveis sob condições alcalinas de $\mathrm{pH}^{1}$.

As coberturas em monocamada podem ser produzidas pela reação do substrato com organossilano contendo apenas um grupo hidrolisável. No entanto, as superfícies resultantes ainda exibem algumas características do mineral precursor, devido à presença de grupos hidroxilas remanescentes ${ }^{2}$.

A silanização em meio aquoso é um método inconveniente por ser difícil controlar a extensão da oligopolimerização em solução, resultando em coberturas de superfície não reprodutíveis. Outros problemas envolvem o processo de cura em que as propriedades do substrato e as espécies em solução interagem com a superfície e influenciam na determinação das características, da recente superfície modificada ${ }^{2}$.

Alguns exemplos desse tipo de processo foram utilizados na obtenção de caulinita modificada com silanos de diferentes funcionalidades $^{29}$ e, também, com a mica ${ }^{30,31}$.

(b) Funcionalização envolvendo a formação de ligações covalentes com a superfície via condensação com os silanóis da superfície, ou com hidroxilas na ausência de água. Deve-se destacar que, para a ocorrência de interação covalente, as reações devem ser conduzidas em atmosfera anidra. Esta condição exige o uso de agentes sililantes e solventes puros, como também a eliminação por aquecimento da água superficial presente na matriz inorgânica precursora. Desse modo, o tratamento térmico adequado a que a amostra será submetida poderá ser decisivo sobre a natureza do produto final ${ }^{32}$. Na literatura poucos trabalhos são citados envolvendo a silanização de filossilicatos nessas condições. Um trabalho recente refere-se à modificação de crisotila com silanos aminados e subseqüente reação com aldeídos ${ }^{33}$ e a silanização do talco com alcoxissilanos aminados de cadeia crescente ${ }^{34}$.

A Figura 6 ilustra as reações de silanização da crisotila, um filossilicato lamelar de estrutura fibrosa.

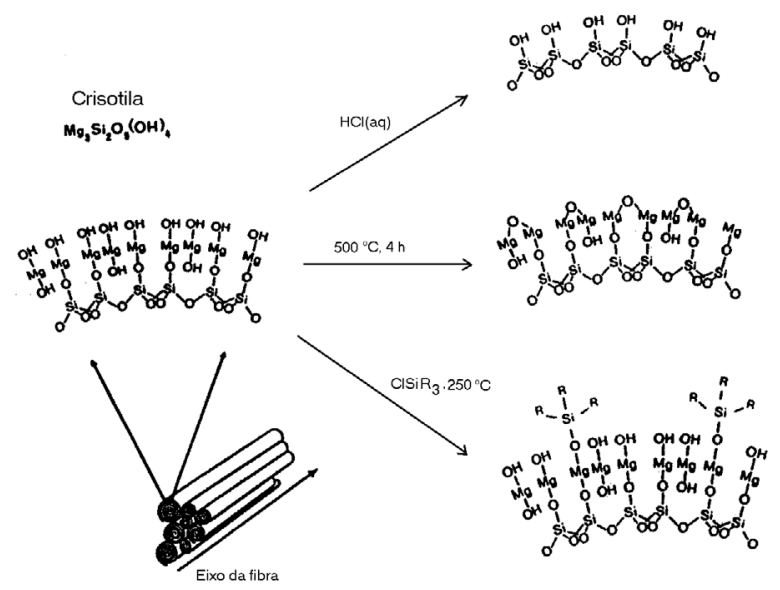

Figura 6. Ilustração da reações de modificação da superfície da crisotila em meio ácido, sob aquecimento e na presença de silanos mostrando sua composição de átomos de silício tetraedricamente coordenados a oxigênios e átomos de magnésio ligados octaedricamente a grupos $\mathrm{OH}$ e oxigênios em uma estrutura tubular

Conforme se observa, a funcionalização da matriz ocorre apenas na superfície do cristal, sendo que a reação envolveu uma substituição nos grupos hidroxilas ligados ao magnésio por espécies $\mathrm{O}_{3} \mathrm{SiR}$, em que R são grupos orgânicos de cadeia crescente contendo nitrogênios. Uma reação semelhante para os derivados de silanização do talco sugere uma estrutura como mostrada na Figura 7, em que os grupos orgânicos derivados dos alcoxissilanos $\left(\mathrm{CH}_{3} \mathrm{O}\right)_{3} \mathrm{SiR}$ (onde $\mathrm{R}=$ $\left(\mathrm{CH}_{2}\right)_{3} \mathrm{NH}_{2},\left(\mathrm{CH}_{2}\right)_{3} \mathrm{NH}\left(\mathrm{CH}_{2}\right)_{2} \mathrm{NH}_{2}$ e $\left.\left(\mathrm{CH}_{2}\right)_{3} \mathrm{NH}\left(\mathrm{CH}_{2}\right)_{2} \mathrm{NH}\left(\mathrm{CH}_{2}\right)_{2} \mathrm{NH}_{2}\right)$ estão ancorados superficialmente via grupos $\mathrm{OH}$ do magnésio ${ }^{34}$.
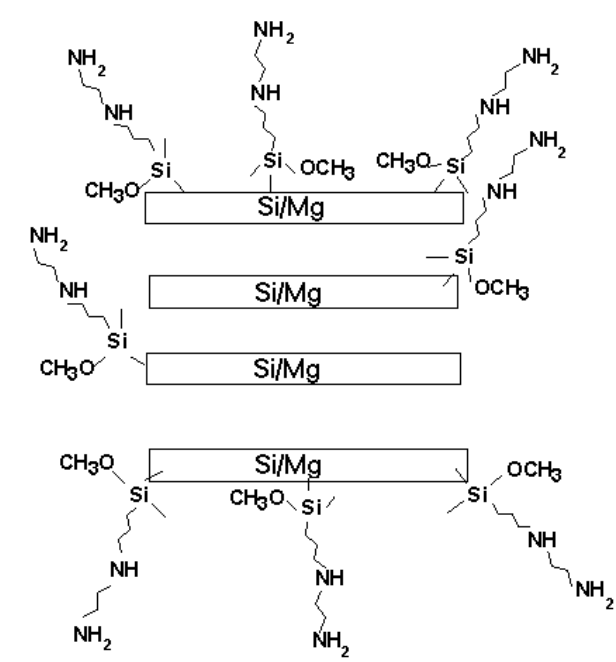

Figura 7. Ilustração de matriz inorgânica lamelar contendo grupos orgânicos ancorados por reação com $\mathrm{OH}$ superficiais

\section{DERIVADOS ORGÂNICOS ENVOLVENDO REAÇÕES NA LACUNA INTERLAMELAR}

A obtenção de derivados orgânicos de minerais também pode 
ocorrer pela incorporação de espécies orgânicas convidadas através de intercalação nas redes hospedeiras lamelares inorgânicas. Este processo permite uma oportunidade única para orientar e manipular espécies intercaladas e alterar reatividade, propriedades eletrônicas e ópticas de ambos, hóspede e hospedeiro, sendo esta uma maneira efetiva para obtenção de nanosistemas inorgânico-orgânicos ${ }^{35-38}$. Os nanocompósitos multilamelares inorgânico-orgânicos têm atraído considerável atenção em anos recentes, devido à grande versatilidade desses sistemas ${ }^{38}$.

Normalmente, os compósitos são formados por duas ou mais fases em escala micrométrica, enquanto que nanocompósitos são materiais obtidos por uma formulação em escala molecular ou nanométrica de, pelo menos, uma das fases, o que permite um aumento da especificidade desses compostos ${ }^{37}$.

Os minerais argilosos formam um grupo de matrizes que têm a capacidade de inserir espécies, daí a denominação de hospedeiros, os quais favorecem a química de intercalação de várias moléculas orgânicas, como aminas alifáticas ou aromáticas ${ }^{39-43}$, organocátions ${ }^{4-49}$, metaloporfirinas $^{50}$, complexos $^{51-57}$ ou polímeros ${ }^{58-67}$. A importância desses derivados está na sua utilização como materiais precursores para pilarização, adsorventes, catalisadores e eletrodos ${ }^{68-71}$. No caso específico da obtenção de materiais pilarizados busca-se geração de porosidade, que direciona a aplicação do material, melhorando suas especificidade e seletividade. Nesse aspecto, devido à natureza expansível, as esmectitas, como a montimorilonita, são bastante utilizadas para intercalação de aminas alifáticas, aromáticas e, mais recentemente, para intercalação de polímeros. Além disso, um outro grupo de filossilicatos cuja utilização tem despertado interesse, compreende a canemita $\left(\mathrm{NaHSi}_{2} \mathrm{O}_{5} \cdot 3 \mathrm{H}_{2} \mathrm{O}\right)$, magadeita $\left(\mathrm{Na}_{2} \mathrm{Si}_{14} \mathrm{O}_{29} \cdot 9 \mathrm{H}_{2} \mathrm{O}\right)$, caniaita $\left(\mathrm{Na}_{2} \mathrm{Si}_{20} \mathrm{O}_{41} \cdot 10 \mathrm{H}_{2} \mathrm{O}\right)$ e macaita $\left(\mathrm{Na}_{2} \mathrm{Si}_{4} \mathrm{O}_{9} \cdot 5 \mathrm{H}_{2} \mathrm{O}\right)^{72}$.

Outros filossilicatos, como a caulinita, devido às ligações de hidrogênio entre as suas lamelas características dos filossilicatos do tipo $1: 1$, têm a capacidade de intercalar diretamente um número limitado de pequenas moléculas hóspedes como N-metilformamida $(\mathrm{NMF})^{73-77}$, dimetilsulfóxido (DMSO) $)^{78,79}$ e nitroanilina ${ }^{80}$, conforme mostra a Figura 8.

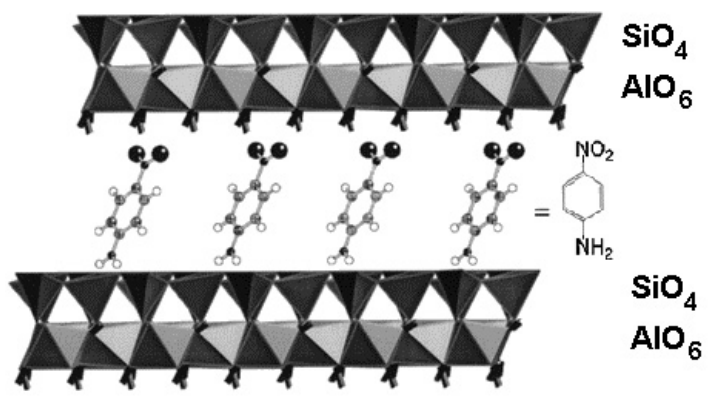

Figura 8. Ilustração de caulinita contendo nitroanilina intercalada

No caso de intercalação de espécies de tamanhos maiores ou mesmo de silanização, uma das rotas tem sido pelo método de deslocamento do hóspede, através do qual novas espécies convidadas podem ser intercaladas, pelo deslocamento de uma entidade previamente inserida, conforme ilustra a Figura 9.

A idéia básica é que o alargamento no espaçamento lamelar permite inserir moléculas maiores, como polímeros ou complexos metálicos, entre as camadas dos silicatos como foi feito com a montmorilonita ${ }^{81}$, conforme apresentado na Figura 10.

No caso de moléculas grandes, como polímeros, a distância lamelar do silicato pode aumentar em tal extensão que ocorre a esfoliação do silicato em dimensão nanométrica e este se dispersa na matriz do polímero, como mostrado na Figura 11.

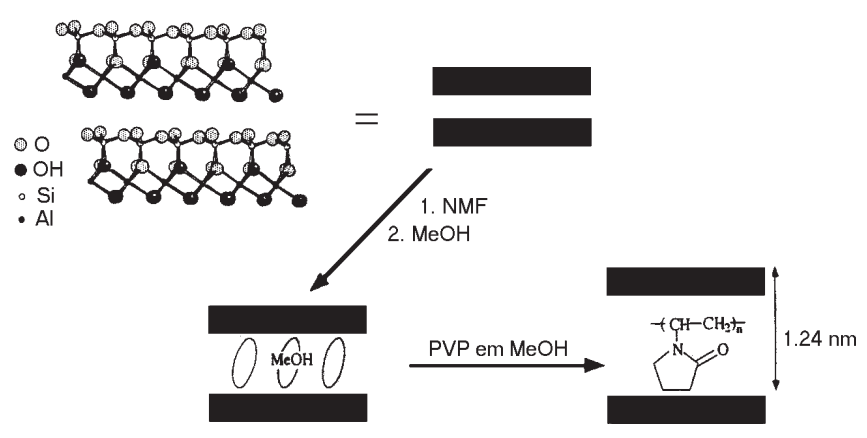

Figura 9. Processo de intercalação de polivinilpirrolidona $(P V P)$ em caulinita, pelo método do deslocamento do convidado ( $\mathrm{NMF}$ e MeOH). Reproduzida da ref. 59, com permissão da American Chemical Society

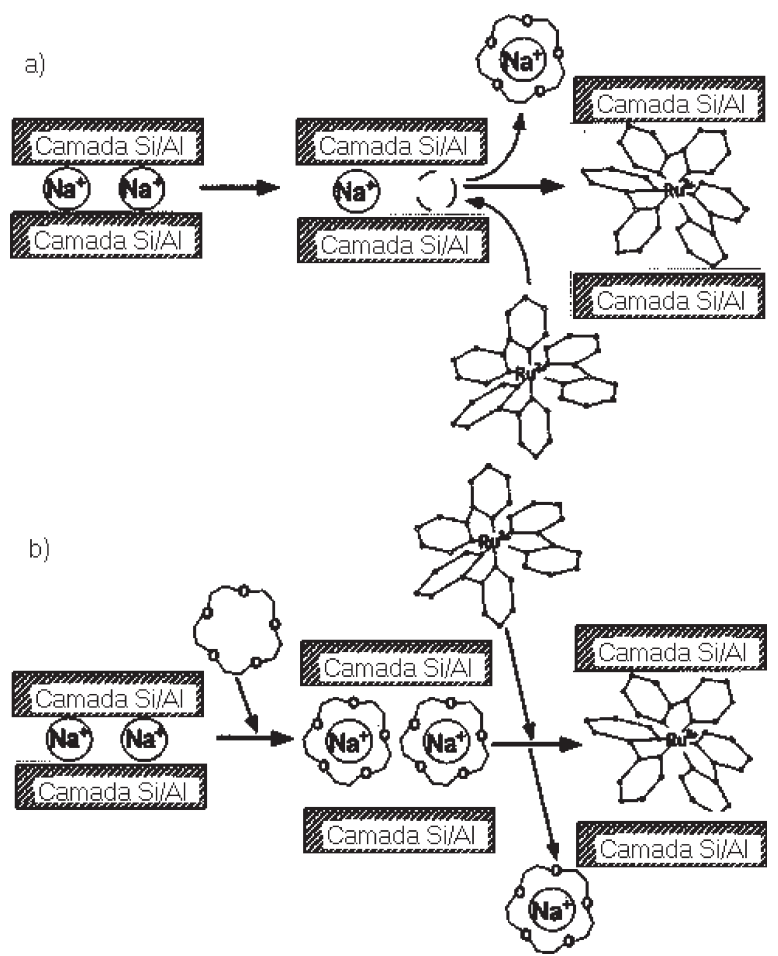

Figura 10. Ilustração da intercalação de um complexo do tris(2,2'bipiridina)rutênio(II) em magadeita, em presença de um éter de coroa. Reproduzida da ref. 81, com permissão da American Chemical Society a)

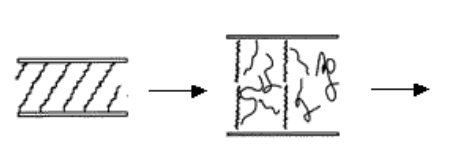

))

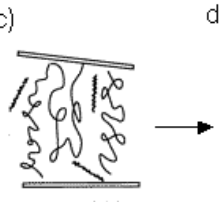

d)

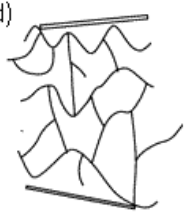

Figura 11. Proposta para a formação de um nanocompósito de epoxi/ magadeita exfoliado: a) organomagadeita original, b) reorientação de íons aquilamônio, permitindo a co-intercalação de epoxi, c) rápida formação de um gel polimerizado e expansão lamelar e d) exfoliação das nanocamadas do silicato. Reproduzida da ref. 62, com permissão da American Chemical Society 
Esses materiais apresentam a combinação única das propriedades de cada componente mas, dependendo da aplicação como em fotoquímica e aplicações ambientais ou como carga, o processo de exfoliação não é desejado.

Uma outra rota, quando a intercalação possui uma cinética lenta, tem sido o uso de ultrasom, no entanto, a desvantagem citada pela literatura é a alteração da estrutura cristalina do hospedeiro ${ }^{82}$.

No caso específico do método de intercalação de moléculas convidadas em filossilicatos seguindo-se de reações de silanização, um exemplo clássico é o trabalho com a magadeita com trimetilclorossilano pela intercalação prévia de NMF entre as lamelas do silicato ${ }^{83,84}$. Neste caso, foi observado que o mecanismo de modificação do filossilicato é controlado pela coesão interlamelar e cinética da reação. A coesão interlamelar devido às ligações de hidrogênio entre camadas adjacentes, é atenuada pela intercalação prévia de moléculas polares ou íons grandes como polioxicátions como, por exemplo, o íon de Keggin $\left[\mathrm{Al}_{13} \mathrm{O}_{4}(\mathrm{OH})_{24}(\mathrm{OH})_{12}\right]^{7+}$, que expandem o espaçamento basal e tornam os grupos $\mathrm{Si}-\mathrm{OH}$ acessíveis aos reagentes ${ }^{85}$.

A cinética dessas reações é governada por dois processos simultâneos: dessorção da molécula pré-intercalada e difusão dos agentes sililantes no espaço lamelar. Recentemente, a magadeita dodeciltrimetilamônio foi utilizada como intermediário para silanização com um fluoroalquilsilano ${ }^{86}$ e canemita silanizada com tricloroalquilsilanos após intercalação prévia de hexadeciltrimetilamônio ${ }^{87}$, como visto na Figura 12.

a)

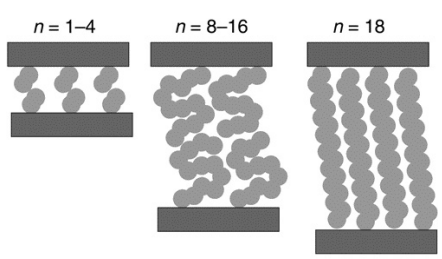

b)

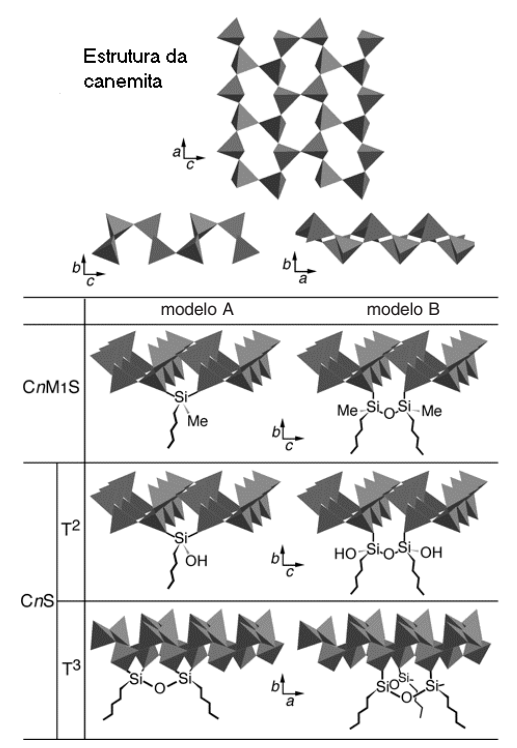

Figura 12. Modelos estruturais propostos para: a) intercalação de álcool de fórmula $\mathrm{C}_{n} \mathrm{H}_{2 n+1} \mathrm{OH}$ em canemita e b) grupos aquilsilil ligados em alquiltriclorosilanos e alquilmetrildiclorosilanos, intercalados em canemita simbolizados por (CnS) e CnM1S, respectivamente. Reproduzida da ref. 87, com permissão da American Chemical Society

A literatura conta com um pequeno número de trabalhos envolvendo a silanização de filossilicatos com a entrada do agente sililante diretamente no espaço interlamelar, ou mesmo na superfície. Entre esses trabalhos destacam-se a silanização da montimorilonita com aminossilanos ${ }^{88}$; da imogolina, um filossilicato tubular, silanizada com aminopropiltrimetoxissilano na presença de água ${ }^{89}$; silanização da crisotila um filossilicato de magnésio $1: 1$ com clorossilanos ${ }^{90} \mathrm{e}$ com aminossilanos, seguida de reação com aldeídos e, recentemente, reação de aminopropiltrimetoxissilano (APTS) com caniaita $\left(\mathrm{Na}_{2} \mathrm{Si}_{22} \mathrm{O}_{45} \cdot 10 \mathrm{H}_{2} \mathrm{O}\right)$, seguida de reação com um dianidrido aromático (BTDA) e oxidianilina polimerizada (ODA) ${ }^{91}$.

\section{DERIVADOS OBTIDOS PELO PROCESSO SOL-GEL}

Em anos recentes, os silicatos lamelares modificados organicamente são normalmente obtidos pelo processo sol-gel que, no caso específico, trata de reações de copolimerização de íons metálicos com trialcoxissilanos do tipo (RO) $\mathrm{Si}_{3}\left(\mathrm{CH}_{2}\right)_{3} \mathrm{X}$, sendo $\mathrm{R}$ um grupo alquila e $\mathrm{X}$ uma função desejada. Desse modo, uma série de compostos híbridos com diferentes funcionalidades pode ser sintetizada, dependendo do agente sililante ou do sal metálico de partida.

Embora exista uma grande variedade de técnicas de síntese envolvendo o processo sol-gel na obtenção de híbridos inorgânicoorgânicos ${ }^{92}$, torna-se difícil entender essas diferentes rotas sem um conhecimento do que seja o processo sol-gel.

O processo sol-gel é baseado na polimerização de precursores moleculares, tais como os alcoxissilanos metálicos $\mathrm{M}(\mathrm{OR})_{\mathrm{n}}{ }^{93}$. As reações de hidrólise e condensação desses alcoxissilanos levam à formação de oxo-polímeros metálicos. Uma das características principais oferecidas pelo processo sol-gel é permitir a inserção de moléculas orgânicas em uma rede polimérica inorgânica. Os componentes inorgânicos e orgânicos desejados podem, então, ser combinados em escala nanométrica, originando os híbridos inorgânico-orgânicos. Esta técnica experimental apresenta algumas vantagens inerentes sobre outras na obtenção desses híbridos, como o controle da estrutura, porosidade com formação de materiais meso ou microporosos, composição homogênea, pureza e habilidade para preparação de materiais modulados com partículas esféricas, fibras ou filmes finos ${ }^{94-96}$.

Esse processo é, geralmente, dividido em dois estágios: hidrólise do alcóxido onde são produzidos os grupos hidroxilas e policondensação dos mesmos com os grupos alcóxido remanescentes, podendo estas reações ocorrerem tanto em meio ácido como bási$\mathrm{co}^{97}$.

As reações de hidrólise de sais inorgânicos e a condensação das espécies hidrolizadas de alcóxido em meio aquoso podem formar uma grande variedade de espécies químicas ${ }^{98}$. Após as reações de hidrólise e subseqüente condensação das espécies hidratadas, podese ter a formação de partículas coloidais ou de cadeias poliméricas lineares, as quais originam dois tipos de géis, que são descritos na literatura como:

(a) géis coloidais - em que os efeitos estéricos ou eletrolíticos no sol dominam a formação do gel. A principal característica desse tipo de gel é a forma como as partículas individuais contidas no sol podem ser arranjadas durante o processo.

(b) géis poliméricos - em que a velocidade e extensão da reação química levam à polimerização de agregados e interpenetração durante a gelatinização.

As reações químicas envolvidas nesse processo podem ser descritas da seguinte maneira:

1. hidrólise do precursor, que leva à formação das ligações M-OH. A hidroxilação de sais inorgânicos é dependente principalmente do $\mathrm{pH}$ da solução aquosa, resultando em um cátion metálico ligado a três tipos diferentes de ligantes: aquo $\left[\mathrm{M}\left(\mathrm{OH}_{2}\right)\right]$, hidroso $[\mathrm{M}-\mathrm{OH}]$ ou oxo $[\mathrm{M}=\mathrm{O}]$ : 
- protonação de oxo-íons aniônicos:

$\mathrm{MO}_{\mathrm{n}}^{\mathrm{x}-}+\mathrm{H}^{+} \rightarrow \mathrm{HMO}_{\mathrm{n}}{ }^{(\mathrm{x}-1)-}$

- desprotonação de aquo-íons catiônicos:

$\mathrm{M}\left(\mathrm{OH}_{2}\right)_{\mathrm{n}}^{\mathrm{z+}} \rightarrow\left[\mathrm{M}(\mathrm{OH})\left(\mathrm{OH}_{2}\right)_{\mathrm{n}-1}\right]^{(\mathrm{z}-1)+}+\mathrm{H}^{+}$

Em geral, a hidrólise é facilitada pelo aumento na densidade de carga no metal, pelo número de íons metálicos ligados por ligante hidroxo ou oxo, e o número de hidrogênios contidos no ligante. A hidrólise é inibida quando se aumenta o número de ligantes hidroxo coordenados ao metal.

Quando se trata de alcóxido, a hidrólise acontece pela adição de água:

$\mathrm{M}(\mathrm{OR})_{\mathrm{n}}+\mathrm{H}_{2} \mathrm{O} \rightarrow \mathrm{M}(\mathrm{OH})(\mathrm{OR})_{\mathrm{n}-1}+\mathrm{ROH}$

2. Em ambos os processos, a etapa posterior envolve reações de condensação que podem se processar por olação e oxolação:

olação: $\quad \mathrm{M}-\mathrm{OH}+\mathrm{H}_{2} \mathrm{O}^{+}-\mathrm{M} \rightarrow \mathrm{M}-\mathrm{HO}^{+}-\mathrm{M}+\mathrm{H}_{2} \mathrm{O}$

$\mathrm{M}-\mathrm{OH}+\mathrm{R}-\mathrm{HO}^{+}-\mathrm{M} \rightarrow \mathrm{M}-\mathrm{HO}^{+}-\mathrm{M}+\mathrm{ROH}$

oxolação: $\mathrm{M}-\mathrm{OH}+\mathrm{HO}-\mathrm{M} \rightarrow \mathrm{M}-\mathrm{O}-\mathrm{M}+\mathrm{H}_{2} \mathrm{O}$

$$
\mathrm{M}-\mathrm{OH}+\mathrm{RO}-\mathrm{M} \rightarrow \mathrm{M}-\mathrm{O}-\mathrm{M}+\mathrm{ROH}
$$

A condensação via olação envolve a reação de hidroxo ou aquo íons do tipo $\left[\mathrm{M}(\mathrm{OH})_{\mathrm{x}}\left(\mathrm{OH}_{2}\right)_{\mathrm{n}-\mathrm{x}}\right]^{\mathrm{(z-x)+}}$, com $\mathrm{x}<\mathrm{n}$, correspondendo a uma substituição nucleofílica, na qual M-OH é o nucleófilo e o ligante aquo é removido da esfera de coordenação. Desse modo, a cinética da reação depende da labilidade da ligação $\mathrm{M}-\mathrm{OH}_{2}$, que consiste em etapa lenta do processo.

A condensação via oxolação é observada na ausência de ligantes aquo na esfera de coordenação do metal, envolvendo freqüentemente a reação de íons oxo-hidroxo $\left[\left(\mathrm{MO}_{\mathrm{x}}(\mathrm{OH})_{\mathrm{n}-\mathrm{x}}\right]^{(\mathrm{n}+\mathrm{x}-\mathrm{z})}\right.$. Quando a esfera de coordenação do metal não está saturada, a reação ocorre por adição nucleofílica. Neste caso, os grupos ligantes não são removidos e a espécie condensada é formada rapidamente. Quando a esfera de coordenação do metal está completamente saturada, pode ocorrer a substituição nucleofílica que compreende, numa primeira etapa, a adição com formação de pontes $\mathrm{OH}$, que são instáveis, seguida da eliminação do grupo de saída $\mathrm{H}_{2} \mathrm{O}$. Essas etapas podem ser catalisadas por bases e ácidos, de modo que a cinética de oxolação é fortemente dependente do $\mathrm{pH}$.

Os primeiros filossilicatos de magnésio e de níquel modificados foram obtidos com grupos metacrilados pela rota sol-gel ${ }^{4}$, envolvendo as reações entre cloretos metálicos de magnésio ou níquel com 3propilmetacrilatotrimetoxissilano catalisadas por base em meio aquoso, como mostra a Figura 13.

Depois dessa investigação, outros filossilicatos modificados de magnésio foram sintetizados contendo os grupos fenil, aminopropil, mercaptopropil, alquil e alquil uréias de cadeias crescentes ${ }^{6,7,9,10,99}$. O interessante é que esses filossilicatos de magnésio modificados têm estrutura similar à do talco. Conforme a literatura, o talco é um filossilicato de magnésio trioctaédrico do tipo 2:1, sendo constituído por uma camada de magnésio octaédrico recheada por duas de sílica tetraédricas ${ }^{16}$.

No caso desses filossilicatos modificados obtidos pelo processo sol-gel, observou-se que entre as lamelas estão presentes os grupos orgânicos, conforme mostra a Figura 14, conferindo ao material fun- a)
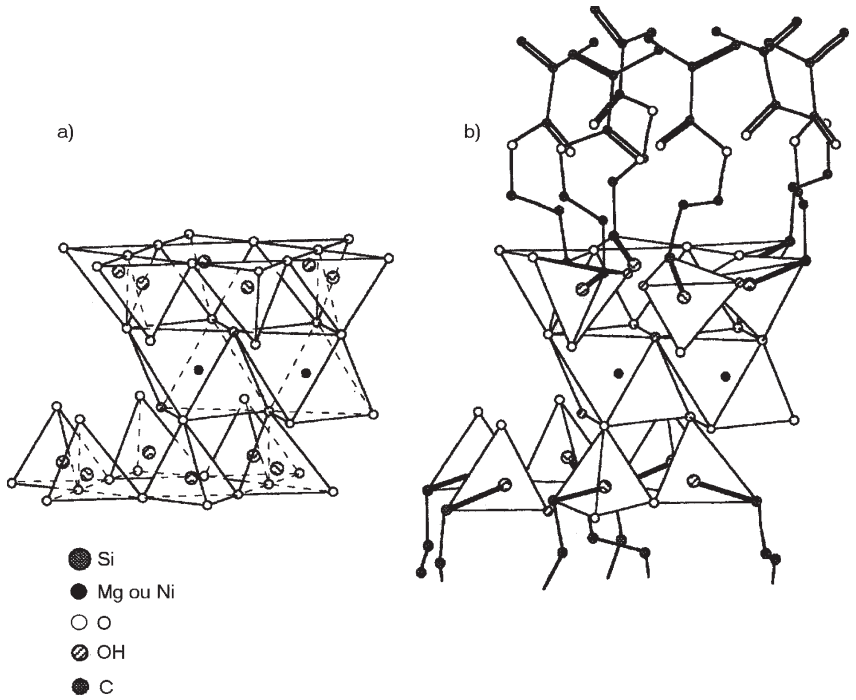

Figura 13. Modelos para estruturas de: a) esmectita e b) filossilicato de magnésio 3-metacrilatopropil

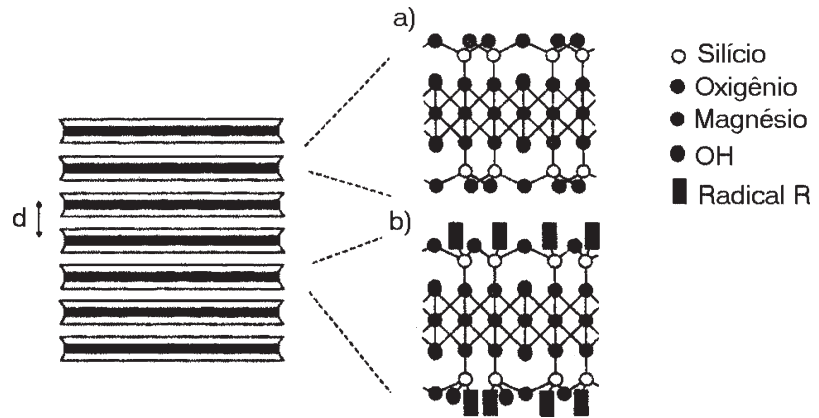

Figura 14. Representação esquemática de estruturas lamelares de a) filossilicatos de magnésio 2:1 trioctaédricos $\mathrm{Si}_{8} \mathrm{Mg}_{6} \mathrm{O}_{20}(\mathrm{OH})_{4}$ e b) $e$ filoorganossilicato de magnésio $\mathrm{Si}_{8} \mathrm{R}_{8} \mathrm{Mg}_{6} \mathrm{O}_{16-x / 2}(\mathrm{OH})_{4+x}$, onde $x=2$. Reproduzida da ref. 9, com permissão de The Royal Society of Chemistry

cionalidades específicas, dependendo da natureza química do grupo $\mathrm{R}$ ligado ao alcoxissilano de partida $\left(\mathrm{CH}_{3} \mathrm{O}\right)_{3} \mathrm{SiR}$.

A importância dessas sínteses está na obtenção de materiais híbridos com estrutura similar ao talco, contendo os grupos orgânicos entre as lamelas e sem as impurezas comumente encontradas na estrutura do mineral ou na superfície, como ferro e níquel, por exemplo. Vale destacar que a obtenção desses compostos pela intercalação direta das moléculas orgânicas na matriz, como se tem feito com esmectitas, não é possível devido à natureza não expansível do talco. Outro aspecto importante é a incompatibilidade do talco natural com materiais orgânicos, limitando sua eficiência como agente de reforço.

Recentemente, alguns filossilicatos modificados com uma estrutura similar a hectorita, como ilustra a Figura 15, foram obtidos pela reação de hidrólise de sais de magnésio e lítio nos alcossilanos feniltrietoxissilano, metacriloxipropiltrimetoxissilano, 3-acriloxipropiltrimetoxissilano e tetraetoxissilano (TEOS) ${ }^{100}$.

$\mathrm{O}$ uso da rota sol-gel anterior, utilizando temperaturas mais ele$\operatorname{vadas}^{101}$, também permitiu a obtenção de outros filossilicatos de níquel modificados organicamente com grupos de amina protonados, como visto na Figura 16.

Uma rota alternativa para obtenção dessas organoargilas seria a síntese hidrotérmica do mineral com a incorporação direta dos agentes entre as lamelas, por difusão na formação da estrutura. No entan- 
(a)

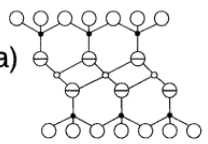

(b)
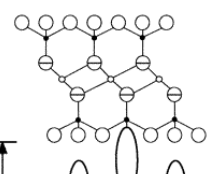

mapopo
0000000
0090
0000<smiles>[3H][13IH]</smiles>

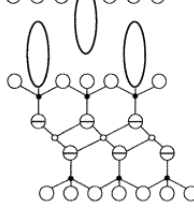

$\mathrm{O}=\mathrm{O}$

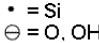

$\circ=\mathrm{Mg}(\mathrm{II}), \mathrm{Li}(\mathrm{I})$

O = Orgânico

Figura 15. Representação de um filossilicato de níquel organomodificado com razão molar $\mathrm{Ni} / \mathrm{Si}=3 / 1$. Reproduzida da ref. 100, com permissão da American Chemical Society

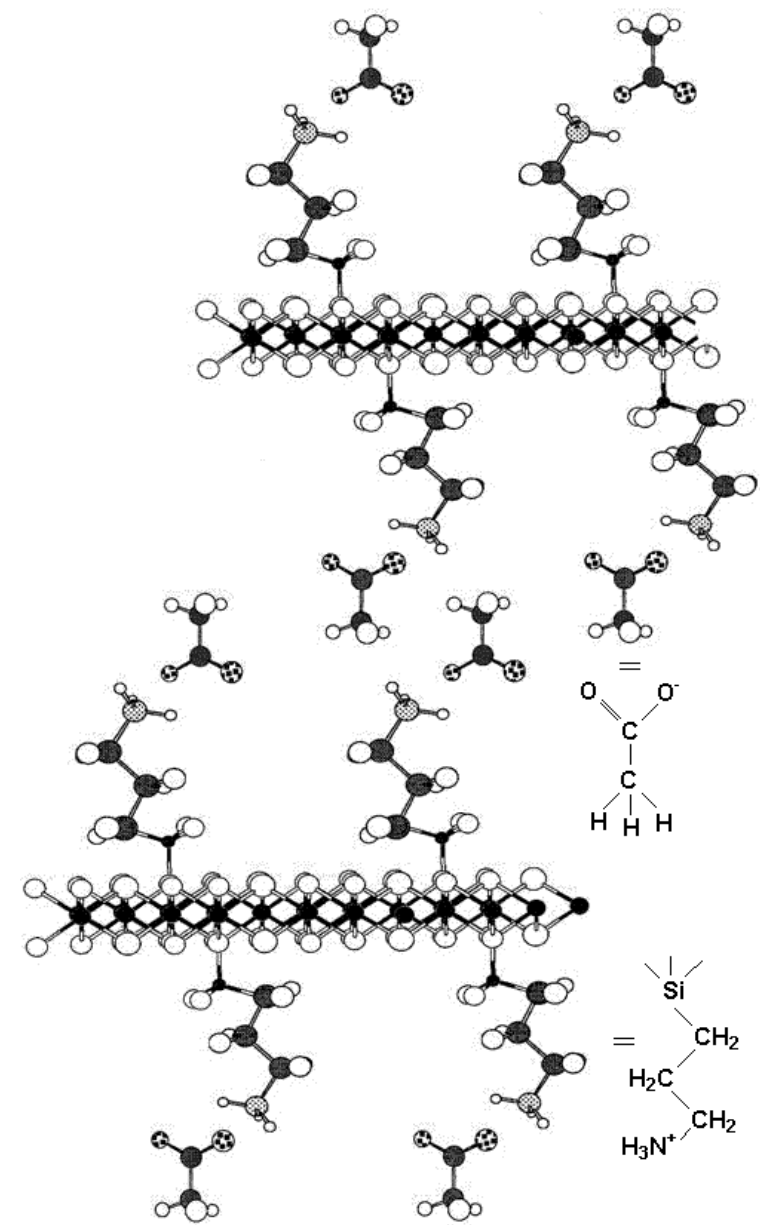

Figura 16. Representação de um filossilicato de níquel modificado com grupos amina. Reproduzida da ref. 101, com permissão da American Chemical Society

to, esses métodos requerem temperaturas altas e condições de reações cuidadosamente controladas, o que acarreta elevado tempo de cristalização dos produtos ${ }^{102}$.

\section{CONSIDERAÇÕES FINAIS}

A síntese de híbridos inorgânico-orgânicos por reações de silanização pode ser estendida para várias superfícies hidroxiladas, como é o caso dos filossilicatos. Apesar da grande variedade de com- postos pertencentes a essa classe, poucos estudos têm sido realizados envolvendo essas matrizes que demonstraram ser bons suportes para espécies diversificadas como as ftalocianinas e hematoporfirinas ${ }^{103}$. Por outro lado, a síntese pelo processo sol-gel tem possibilitado a obtenção de estruturas similares, porém com alto grau de pureza e homogeneidade, ampliando o uso desses híbridos em áreas como catálise, processos de separação e eletroquímica.

\section{AGRADECIMENTOS}

Os autores agradecem à FAPESP pelo apoio financeiro, à CA$\mathrm{PES} / \mathrm{PICD} / \mathrm{UEPB}$ e ao $\mathrm{CNPq}$ pelas bolsas concedidas.

\section{REFERÊNCIAS}

1. Leyden, D. E.; Collins, W. T.; Silylated Surfaces, Gordon Breach Science: New York, 1980.

2. Leyden, D. E.; Luttrell, H. G.; Anal. Chem. 1975, 47, 1612.

3. Pinnavaia, T. J.; Science 1983, 220, 365.

4. Fukushima, Y.; Tami, M.; Chem. Commun. 1995, 24

5. Fukushima, Y.; Tami, M.; Bull. Chem. Soc. Jpn. 1996, 69, 3667.

6. Burkett, S. L.; Press, A.; Mann, S.; Chem. Mater. 1997, 9, 1071.

7. Ukrainczyk, L. J.; Phys. Chem. B. 1997, 101, 531.

8. Hong, Y-S.; Kim, S-J.; Bull. Korean Chem. Soc. 1997, 18, 2.

9. Whilton, W.; Burkett, S. L.; Mann, S.; J. Mater. Chem. 1998, 8, 1927.

10. Fonseca, M. G.; Silva, C. R.; Airoldi, C.; Langmuir 1999, 15, 5048.

11. Fonseca, M. G.; Silva, C. R.; Barone, J.; Airoldi, C.; J. Mater. Chem. 2000, 3,789 .

12. Fonseca, M. G.; Airoldi, C.; J. Mater. Chem. 2000, 10, 1457.

13. Souza, P. S.; Tecnologia das Argilas, Ed. da USP/Edgard Bluecher Ltda: São Paulo, 1975, vol. 1.

14. Pergher, S. B. C.; Corma, A.; Fornés, V.; Quim. Nova 1999, 22, 693.

15. Brindely, G. W.; Brown, G.; Crystal Structures of Clay Minerals and their X-Ray Identification, 1st ed., Mineralogical Society: London, 1980.

16. Velde, B.; Introduction to Clay Minerals, Chapman \& Hall: Londres, 1992.

17. Newman, A. C. D.; Chemistry of Clays and Clays Minerals, Longman Scientific Technical: London, 1987.

18. Gomes, C. F.; Argilas: O que são e para que servem?, Fundação Calouste Gulbenkian: Lisboa, 1986.

19. Tunney, J. J.; Detelier, C.; Chem. Mater. 1993, 5, 747.

20. Tunney, J. J.; Detelier, C.; Clays Clay Miner. 1994, 42, 473.

21. Tunney, J. J.; Detelier, C.; Clays Clay Miner. 1994, 42, 552.

22. Cruz, M. D. R.; Franco, F.; Clays Clay Miner. 2000, 48, 63.

23. Guimarães, J. L.; Peralta-Zamora, P.; Wypych, F.; J. Colloid Interface Sci. 1998, 206, 281

24. Guimarães, J. L.; Marangoni, R.; Ramos, L. P.; Wypych, F.; J. Colloid Interface Sci. 2000, 227, 445.

25. Komori, Y.; Enoto, H.; Takenawa, R.; Hayashi, S.; Sugahara, Y.; Kuroda K.; Langmuir 2000, 16, 5506.

26. Gardolinski, J. E.; Wypych, F.; Cantão, M. P.; Quim. Nova 2001, 6, 761.

27. Wight, P. A.; Davis, M. E.; Chem. Rev. 2002, 102, 3589.

28. Arakaki, L. N. H.; Airoldi, C.; Quim. Nova 1999, 22, 246.

29. Johansson, U.; Holmgren, A.; Forsling, W.; Frost, R. L.; Clays Clay Miner. 1999, 34, 239.

30. Brunner, H.; Vallant, T.; Mayer U.; Hoffmann, H.; Basnar, B.; Vallant, M.; Friedbacher, G.; Langmuir 1999, 15, 1899

31. Tian, F.; Xiao, X.; Toy, M. M. T.; Langmuir 1999, 15, 244.

32. Silva, C. R.; Jardim, I. C. S. F.; Airoldi, C.; J. High Res. Chromatogr. 1999, $22,103$.

33. Fonseca, M. G.; Airoldi, C.; J. Mater. Chem. 1999, 9, 1375.

34. Fonseca, M. G.; Airoldi, C.; Mater. Res. Bull. 2001, 36, 277.

35. Schöllhorn, R.; Chem. Mater. 1996, 8, 1747.

36. Ohtsuka, K.; Chem. Mater. 1997, 9, 2039.

37. Clearfield, A.; Chem. Mater. 1998, 10, 280.

38. Wang, J.; Merino, J.; Aranda, P.; Galván, J-C.; Ruiz-Hitzky, E.; J. Mater. Chem. 1999, 9, 161

39. Beneke, K.; Lagaly, G.; Am. Mineral. 1977, 62, 763.

40. Lagaly, G.; Angew. Chem., Int. Ed. 1976, 15, 875.

41. Chaussidon, J.; Calvet, R.; J. Phys. Chem. 1965, 69, 2265.

42. Sohn, J. R.; Lee, S.; Langmuir 2000, 16, 5024.

43. Chattopadhyay, S.; Traina, S. J.; Langmuir 1999, 15, 1634

44. Yanagisawa, T.; Shimizu, T.; Kurosa, T.; Kato, C.; Bull. Chem. Soc. Jpn. 1990, 63, 988 
45. Vahedi-Faridi, A.; Guggenheim, S.; Clays Clay Miner. 1997, 45, 859.

46. Haro, M. C. J.; Ruiz-Conde, A.; Pérez-Rodríguez, J. L.; Clays Clay Miner. 1998, 46, 687.

47. Corma, A.; Chem. Rev. 1995, 95, 559.

48. Lin, C-L.; Pinnavaia, T. J.; Chem. Mater. 1991, 3, 213.

49. Deng, Z. Q.; Lambert, J. F.; Fripiat, J. J.; Chem. Mater. 1989, 1, 375.

50. Martinez-Lorenti, M. A.; Battioni, P.; Kleemiss, W.; Bartoli, J. F.; Mansuy, D.; J. Mol. Catal. A: Chem. 1996, 113, 346.

51. Pinnavaia, T. J.; Raythatha, R.; Lee, J.G-S.; Halloranand, L. J.; Hoffman, J. F.; J. Am. Chem. Soc. 1979, 101, 6891.

52. Giannelis, E. P.; Rightor, E. G.; Pinnavaia, T. J.; J. Am. Chem. Soc. 1988, 110,3880 .

53. Usami, H.; Nakamura, T.; Makino, T.; Fujimatsu H.; Ogasawara, S.; J. Chem. Soc., Faraday Trans. 1998, 94, 83.

54. Brien, S. O'; Keates, J. M.; Barlow, S.; Druwitt, M. J.; Payne, B. R.; Hare D. O'.; Chem. Mater. 1998, 10, 4088.

55. Thomas, S. M.; Bertrand, J. A.; Occelli, M. L.; Stencel, J. M.; Gould, S. A. C.; Chem. Mater. 1999, 11, 1153.

56. Thomas, S.; Bertand, J. A.; Occelli, M. L.; Chem. Mater. 1999, 11, 184

57. Kwon, O-Y.; Shin, H-S.; Choi, S-W.; Chem. Mater. 2000, 12, 1273.

58. Sugahara, Y.; Sugiyama, T.; Kuroda, K.; Kato, C.; Clays Clay Miner. 1988, $36,343$.

59. Komori, Y.; Sugihana, Y.; Kuroda, K.; Chem. Mater. 1999, 11, 3.

60. Shi, H.; Lan, T.; Pinnavaia, T. J.; Chem. Mater. 1996, 8, 1584.

61. Laus, M.; Camerani, M.; Lelli, M.; Sparnacci, K.; Sandnolini, F.; J. Mater Sci. 1998, 33, 2883.

62. Wang, Z.; Pinnavaia, T. J.; Chem. Mater. 1998, 10, 1820.

63. Matsuyama, H.; Young, J. F.; Chem. Mater. 1999, 11, 16.

64. Fiounaris, K. G.; Karakassides, M. A.; Petridis, P.; Chem. Mater. 1999, 11, 2372.

65. Burnside, S. D.; Wang, H-C.; Giannellis, E. P.; Chem. Mater. 1999, 11, 1055.

66. Ogawa, M.; Tsujimura, M.; Kuroda, K.; Langmuir 2000, 16, 4055.

67. Okamoto, M.; Nam, P. H.; Maiti, P.; Kotaka, T.; Hasegawa, N.; Usuki, A.; Nano Lett. 2001, 1, 295.

68. Ohtsuka, K.; Chem. Mater. 1997, 9, 2039.

69. Boury, B.; Corriu, R. J. P.; Strat, V. L.; Chem. Mater. 1999, 11, 2796.

70. Luna, F. J.; Schuchardt, U.; Quim. Nova 1999, 22, 104.

71. Mercier, L.; Detellier, C.; Environ. Sci. Technol. 1995, 29, 1318.

72. Pergher, S. B. C.; Corma, A.; Fornes, V.; Quim. Nova 1999, 22, 693.

73. Theng, B. K. G.; The Chemistry of Clay-Organic Reactions, John Wiley \& Sons: Oxford, 1974.
74. Tunney, J. J.; Detellier, C.; Chem. Mater. 1996, 8, 927.

75. Xie, X.; Hayashi, S.; J. Phys. Chem. B 1999, 103, 5949.

76. Xie, X.; Hayashi, S.; J. Phys. Chem. B 1999, 103, 5956.

77. Tunney, J. J.; Detellier, C.; J. Mater. Chem. 1996, 6, 1679.

78. Tunney, J. J.; Detellier, C.; Chem. Mater. 1993, 5, 747.

79. Hayashi, S.; Clays Clay Miner. 1997, 45, 724.

80. Takenawa, R.; Komori, Y.; Hayashi, S.; Kawamata, J.; Kuroda, K.; Chem. Mater. 2001, 13, 3741 .

81. Ogawa, M.; Takizama, Y.; J. Phys. Chem. B 1999, 103, 5005.

82. O’Hare, D. W. Em Inorganic Materials; Bruce, D. W.; O’Hare, D., eds.; Jonh Wiley \& Sons: New York, 1997, cap. 4.

83. Ruiz-Hitzky, E.; Rojo, J. M.; Lagaly, G.; Colloid Polym. Sci. 1985, 263, 1025.

84. Ruiz-Hitzky, E.; Rojo, J. M.; Nature 1980, 287.

85. Wong, S. T.; Cheng, S.; Chem. Mater. 1993, 5, 770.

86. Ogawa, M.; Miyoshi, M.; Kuroda, K.; Chem. Mater. 1998, 10, 3787.

87. Shimojima, A.; Mochizuki, D.; Kuroda, K.; Chem. Mater. 2001, 13, 3603.

88. Mukkanti, K.; Rao, Y. W. S.; Tetrahedron Lett. 1989, 30, 251.

89. Johnson, L. M.; Pinnavaia, T. J. Em Chemically Modified Surfaces in Science and Industry; Leyden, D. E.; Collins, W. T., eds.; Gordon and Brech Science Publishers: New York, 1986, vol. 3, p. 583.

90. Benett, J. A.; Schweikert, E. A.; Poisson, D.; Joliceur, C.; Surf. Interface Anal. 1990, 15, 651 .

91. Leu, C-M.; Wu, Z-W.; Wei, K-H.; Chem. Mater. 2002, 14, 3016.

92. Wen, J.; Wilkes, G. L.; Chem. Mater. 1996, 8, 1667.

93. Brinker, C. J.; Scherer, G. W.; Sol-Gel Science - The Physics and Chemistry of Sol-Gel Processing, Academic Press: New York, 1990.

94. Gill, I.; Ballesteros, A.; J. Am. Chem. Soc. 1998, 120, 8587.

95. Guizard, C. G.; Julbe, A. C.; Agral, A.; J. Mater. Chem. 1999, 9, 55

96. Sanchez, C.; Ribot, F.; Lebeau, B.; J. Mater. Chem. 1999, 9, 35.

97. Silva, C. R.; Airoldi, C.; J. Colloid Interface Sci. 1997, 195, 381.

98. Hiratsuka, R. S.; Santilli, C. V.; Pulcinelli, S. H.; Quim. Nova 1997, 20, 191.

99. Silva, C. R; Fonseca, M. G.; Barone, J.; Airoldi, C.; J. Mater. Chem. 2002, 14,175

100. Carrado, K. A.; Xu, L.; Csencsits, R.; Muntean, J. V.; Chem. Mater. 2001, $13,3766$.

101. Pouet, M. R.; Vilminot, S.; Guillot, M.; Kurmoo, M.; Chem. Mater. 2002, $14,3829$.

102. Vynck, I.; Silicates Industriels 1980, 3, 51.

103. Fonseca, M. G.; Pessoa, C.; Gushikem, Y.; Airoldi, C.; trabalho não publicado. 